\title{
Article
}

\section{The Association between Socioeconomic Status and Psychological Distress: A Within and Between Twin Study}

\author{
Janine R. Lam ${ }^{1}$, Jessica Tyler ${ }^{1}$, Katrina J. Scurrah², Nicola J. Reavley ${ }^{3}$ and Gillian S. Dite ${ }^{2}$ \\ ${ }^{1}$ Twins Research Australia, Centre for Epidemiology and Biostatistics, Melbourne School of Population and Global Health, The University of Melbourne, \\ Melbourne, Victoria, Australia, ${ }^{2}$ Centre for Epidemiology and Biostatistics, Melbourne School of Population and Global Health, The University of Melbourne, \\ Melbourne, Victoria, Australia and ${ }^{3}$ Centre for Mental Health, Melbourne School of Population and Global Health, The University of Melbourne, Melbourne, \\ Victoria, Australia
}

\begin{abstract}
Low socioeconomic status (SES) has been established as a risk factor for poor mental health; however, the relationship between SES and mental health problems can be confounded by genetic and environmental factors in standard regression analyses and observational studies of unrelated individuals. In this study, we used a within-pair twin design to control for unmeasured genetic and environmental confounders in investigating the association between SES and psychological distress. We also employed within-between pair regression analysis to assess whether the association was consistent with causality. SES was measured using the Index of Relative Socio-economic Disadvantage (IRSD), income and the Australian Socioeconomic Index 2006 (AUSEI06); psychological distress was measured using the Kessler 6 Psychological Distress Scale (K6). Data were obtained from Twins Research Australia's Health and Lifestyle Questionnaire (2014-2017), providing a maximum sample size of 1395 pairs. Twins with higher AUSEI06 scores had significantly lower K6 scores than their co-twins after controlling for shared genetic and environmental traits $\left(\beta_{\mathrm{W}}\right.$ [within-pair regression coefficient] $=-0.012$ units, $\left.p=.006\right)$. Twins with higher income had significantly lower K6 scores than their co-twins after controlling for familial confounders $\left(\beta_{\mathrm{W}}=-0.182\right.$ units, $\left.p=.002\right)$. There was no evidence of an association between the IRSD and K6 scores within pairs $\left(\beta_{\mathrm{W}}, p=.6\right)$. Using a twin design to eliminate the effect of potential confounders, these findings further support the association between low SES and poor mental health, reinforcing the need to address social determinants of poor mental health, in addition to interventions targeted to individuals.
\end{abstract}

Keywords: Between; between-pair; design; differences; Kessler; mental health; model; psychological distress; socioeconomic status; twin; within; within-pair

(Received 4 July 2019; accepted 9 September 2019)

Mental disorders are a leading contributor to the burden of disease worldwide (Whiteford et al., 2013). Reducing this burden requires improving access to quality treatment as well as better understanding and addressing the risk factors for mental disorders.

Several epidemiological studies have shown that low socioeconomic status (SES) is linked to an increased risk of mental disorders (Lorant et al., 2003; Marmot et al., 1991; World Health Organization, 2014). These include studies that have defined SES as income, occupational class (where occupations are categorized by hierarchy) or as an index based on a combination of SES indicators. Lower income, occupational class and SES indices have all been associated with higher risks of having mental health problems in large national studies (Fryers et al., 2003; Lorant et al., 2003).

\section{Controlling for Familial Confounding}

Analysis of the relationship between SES and mental health problems can be influenced by familial confounders (i.e., genetic

Author for correspondence: Janine R. Lam, Email: janine.lam@gmail.com

Cite this article: Lam JR, Tyler J, Scurrah KJ, Reavley NJ, and Dite GS. (2019) The Association between Socioeconomic Status and Psychological Distress: A Within and Between Twin Study. Twin Research and Human Genetics 22: 312-320, https://oi.org/ 10.1017/thg.2019.91 and environmental factors shared by family members) in studies of unrelated individuals when using simple regression models. For example, genes and the early family environment have been shown to influence choice of residence by postcode (Whitfield et al., 2005). Failing to account for these influences can bias the association between SES and mental health problems. Using data from twins allows us to control for confounders because identical twin-pairs share approximately $100 \%$ of their genes, nonidentical twins share approximately $50 \%$ of their genes, and the early environment (in utero and family upbringing) is assumed to be shared to the same extent by both identical and nonidentical twin-pairs. While twin data help control for genetic and early environmental confounders shared by twin-pairs, the study results have potential to benefit the whole population.

\section{Within-Pair Twin Studies}

Two previous twin studies have examined the association between SES and mental health by studying differences in exposures and outcomes within twin-pairs. Within-pair estimates of the association between exposure and outcome account for genetic and environmental traits that twins share.

Cohen-Cline et al.'s (2018) study of cross-sectional data from 3738 same-sex twin-pairs investigated whether higher SES was 
associated with fewer depressive symptoms (Cohen-Cline et al., 2018). When examining the association in twin-pairs, a difference of 10 units in neighborhood socioeconomic deprivation within pairs was associated with $6 \%$ greater severity in depressive symptoms $(95 \% \mathrm{CI}[1.01,1.11])$ after adjusting for the mean deprivation score within a pair.

Osler et al.'s (2007) cross-sectional study of 1266 same-sex Danish twin-pairs investigated whether differences in SES within twin-pairs were associated with symptoms of depression in middle age (Osler et al., 2007). In contrast to most other health outcomes, there were no significant results for depression.

While accounting for genetic and environmental factors, these two twin studies provide mixed evidence for the association between SES and mental health problems. Cohen-Cline et al.'s (2018) study provides support for the association between lower SES and poorer mental health problems, while Osler et al.'s (2007) study did not find evidence for an association. These studies may have reached different conclusions due to methodological differences. Both studies restricted the definition of mental health problems to depression, and Cohen-Cline et al.'s measure of depression only contained two items. Osler et al.'s study focused on adults in middle age, but mental health varies over the life course, with higher prevalence of common mental disorders seen in young adults (Slade et al., 2009).

We contributed to the existing work on SES and mental health by analyzing data from a major Australian twin dataset, using three SES indicators (including two validated measures) and a sensitive measure of psychological distress. We chose to examine the impact of SES on psychological distress, rather than the reverse, given that SES is a well-established social determinant of mental health (World Health Organization, 2014).

\section{Aims and Objectives}

Our study employed a twin design (Hopper \& Seeman, 1994; Sun et al., 2009) to control for unmeasured genetic and environmental confounders when analyzing differences (within-pair effects) and between-pair effects in SES and psychological distress between twins. Using data from Twins Research Australia's (TRA) Health and Lifestyle Questionnaire (HLQ; TRA, 2018), we investigated whether there is an association between SES and psychological distress.

\section{Methods}

\section{Subjects}

The data for this study were collected by TRA from 2014 to 2017 using an online questionnaire (TRA, 2018). Participants were recruited through TRA's website, newsletters and social media channels. The adult version of the questionnaire collects information on demographic background, and health and lifestyle data, including the Kessler 6 Psychological Distress Scale (K6) score, income, employment, occupation, postcode and zygosity. For this study, both twins in a pair had to have completed the HLQ and be aged 18 years or older.

TRA extracted data on K6 scores, occupation (to derive Australian Socioeconomic Index 2006 [AUSEI06] scores, described later), income, postcodes (to derive the Index of Relative Socioeconomic Disadvantage [IRSD] deciles), age at questionnaire completion, sex, zygosity, marital status, general health, education and alcohol consumption. There were 1831 twin-pairs in the data file for this study.
Table 1. AUSEI06 scoring for ANZSCO groups

\begin{tabular}{lc}
\hline ANZSCO major group & $\begin{array}{c}\text { Range of AUSEI06 scores } \\
\text { for ANZSCO groups }\end{array}$ \\
\hline Managers & $34.0-81.5$ \\
\hline Professionals & $66.2-100.0$ \\
\hline Technicians and trades workers & $17.7-63.6$ \\
\hline Community and personal service workers & $29.4-82.3$ \\
\hline Clerical and administrative workers & $32.9-67.4$ \\
\hline Sales workers & $27.8-56.3$ \\
\hline Machinery operators and drivers & $3.4-35.7$ \\
\hline Laborers & $0.0-28.1$ \\
\hline
\end{tabular}

Note: Data sourced from McMillan, Jones et al. (2009).

\section{Exposures: Derived SES Indicators}

Occupational class: AUSEIO6 score. We classified occupation using the AUSEI06, which is based on the Australian and New Zealand Standard Classification of Occupations (ANZSCO) coding (McMillan, Beavis et al., 2009; McMillan, Jones et al., 2009). ANZSCO classifies occupations for statistical analysis (Australian Bureau of Statistics, 2006b), and the validated AUSEI06 enables researchers to convert ANZSCO codes into occupational status scores. AUSEI06 scores occupations from 0 to 100 (with lower scores indicating less education, less skill required, lower income, and so forth).

As recommended by McMillan, Jones et al. (2009), occupations were coded to the four-digit unit group level of ANZSCO for compatibility with AUSEI06 scoring. The ANZSCO codes were then converted to AUSEI06 scores in line with McMillan et al. (McMillan, Beavis et al., 2009) (see Table 1).

Area-level SES: IRSD decile. We also used the ABS's validated IRSD to measure SES, following recent studies' use of this indicator (Scurrah et al., 2016; Sugiyama et al., 2016). As the IRSD is commonly used and appropriate for this research question, it was preferred over the Index of Relative Socio-Economic Advantage and Disadvantage, which ranks areas by socioeconomic advantage and disadvantage. The IRSD is based on indicators of disadvantage from the Census of Population and Housing information (Pink, 2013), including low income, unemployment, educational attainment, one-parent families with dependent children and long-term health conditions or disability. As per the Australian Bureau of Statistics (ABS)' recommendations, we used IRSD deciles in the analysis for ease of interpretation (Pink, 2013).

Income. For income, the original HLQ categories were used (see Table 2). The categories ranged from $\$ 0$ to $\$ 126,000$ and over per annum.

Outcome: The Kessler Psychological Distress Scale. The HLQ used the K6 to measure mental health. The K6 is a commonly used six-item measure of mental wellbeing and is a truncated version of the K10, which contains 10 questions. The survey asks: 'During the last 30 days, about how often did you feel the following?' 'Nervous', 'Hopeless', 'Restless or fidgety', 'So depressed nothing could cheer you up', 'That everything was an effort', 'Worthless'. The scores of the six items are totalled to produce an overall score. Both versions were designed as part of the United States National Health Survey 
Table 2. Distribution of categorical variables for extracted data of 3636 twin individuals, excluding pilot data

\begin{tabular}{|c|c|c|}
\hline \multirow[b]{2}{*}{ Variable } & \multicolumn{2}{|c|}{$\begin{array}{c}\text { Twin } \\
\text { individuals }\end{array}$} \\
\hline & $n$ & $\%$ \\
\hline \multicolumn{3}{|l|}{ Income (per annum) } \\
\hline None & 248 & 6.82 \\
\hline$\$ 1-\$ 15,600$ & 326 & 8.97 \\
\hline$\$ 15,601-\$ 31,200$ & 437 & 12.02 \\
\hline$\$ 31,200-\$ 52,000$ & 541 & 14.88 \\
\hline$\$ 52,001-\$ 78,000$ & 718 & 19.75 \\
\hline$\$ 78,001-\$ 104,000$ & 529 & 14.55 \\
\hline$\$ 104,001-\$ 126,000$ & 196 & 5.39 \\
\hline$\$ 126,000$ and over & 253 & 6.96 \\
\hline Don't know/Prefer not to answer & 388 & 10.67 \\
\hline Total & 3636 & \\
\hline \multicolumn{3}{|l|}{ IRSD decile } \\
\hline 1 & 114 & 3.14 \\
\hline 2 & 208 & 5.72 \\
\hline 3 & 199 & 5.47 \\
\hline 4 & 290 & 7.98 \\
\hline 5 & 300 & 8.25 \\
\hline 6 & 312 & 8.58 \\
\hline 7 & 302 & 8.31 \\
\hline 8 & 456 & 12.54 \\
\hline 9 & 598 & 16.45 \\
\hline 10 & 665 & 18.29 \\
\hline Missing & 192 & 5.28 \\
\hline Total & 3636 & \\
\hline \multicolumn{3}{|l|}{ Confounders } \\
\hline \multicolumn{3}{|l|}{ Sex } \\
\hline Female & 2809 & 77.26 \\
\hline Male & 827 & 22.74 \\
\hline Total & 3636 & \\
\hline \multicolumn{3}{|l|}{ Zygosity } \\
\hline Identical (monozygotic) & 2714 & 74.64 \\
\hline Nonidentical (dizygotic) & 922 & 25.36 \\
\hline Total & 3636 & \\
\hline \multicolumn{3}{|l|}{ Marital status } \\
\hline Married/de facto & 2385 & 65.59 \\
\hline Widowed & 87 & 2.39 \\
\hline Divorced & 258 & 7.10 \\
\hline Separated but not divorced & 92 & 2.53 \\
\hline Never married & 804 & 22.11 \\
\hline Don't know/Prefer not to answer & 10 & 0.28 \\
\hline Total & 3636 & \\
\hline \multicolumn{3}{|l|}{ Highest school grade completed } \\
\hline$\leq$ Year 8 & 47 & 1.29 \\
\hline Year 9 or equivalent & 108 & 2.97 \\
\hline Year 10 or equivalent & 502 & 13.81 \\
\hline
\end{tabular}

Table 2. (Continued)

\begin{tabular}{|c|c|c|}
\hline \multirow[b]{2}{*}{ Variable } & \multicolumn{2}{|c|}{$\begin{array}{l}\text { Twin } \\
\text { individuals }\end{array}$} \\
\hline & $n$ & $\%$ \\
\hline Year 11 or equivalent & 287 & 7.89 \\
\hline Year 12 or equivalent & 2470 & 67.93 \\
\hline Don't know/Prefer not to answer & 20 & 0.55 \\
\hline Missing & 202 & 5.55 \\
\hline Total & 3636 & \\
\hline \multicolumn{3}{|l|}{ Highest post-school qualifications completed } \\
\hline \multicolumn{3}{|l|}{ Vocational Education and Training (VET) } \\
\hline Certificate I or II & 95 & 2.61 \\
\hline VET certificate III or IV or trade certificate & 411 & 11.30 \\
\hline VET diploma or advanced diploma & 319 & 8.77 \\
\hline Bachelor's degree & 901 & 24.78 \\
\hline Graduate diploma or graduate certificate & 639 & 17.57 \\
\hline Postgraduate degree (Masters/PhD) & 478 & 13.15 \\
\hline None & 698 & 19.20 \\
\hline Missing & 95 & 2.61 \\
\hline Total & 3636 & \\
\hline
\end{tabular}

\begin{tabular}{lrr}
\hline Tertiary & 2686 & 73.87 \\
\hline High school & 728 & 20.02 \\
\hline Missing & 222 & 6.11 \\
\hline Total & 3636 & \\
\hline General health & & \\
\hline Excellent & 1013 & 27.86 \\
\hline Very Good & 1552 & 42.68 \\
\hline Good & 765 & 21.04 \\
\hline Fair & 246 & 6.77 \\
\hline Poor & 59 & 1.62 \\
\hline Don't know/Prefer not to answer & 1 & 0.03 \\
\hline Total & 3636 & \\
\hline Derived general health variable used in models & & \\
\hline Good & 3330 & 91.61 \\
\hline Poor & 305 & 8.39 \\
\hline Total & 3635 & \\
\hline $\begin{array}{l}\text { In the last 12 months, how often did you have an alcoholic } \\
\text { drink of any kind? }\end{array}$ & & \\
\hline Fver & & \\
\hline
\end{tabular}

\begin{tabular}{lrr}
\hline Every day & 205 & 5.64 \\
\hline 5-6 days per week & 403 & 11.08 \\
\hline 3-4 days per week & 527 & 14.49 \\
\hline 1-2 days per week & 770 & 21.18 \\
\hline 2-3 days per month & 536 & 14.74 \\
\hline About 1 day per month & 284 & 7.81 \\
\hline Less often & 519 & 14.27 \\
\hline Don't know/Prefer not to answer & 5 & 0.14 \\
\hline Missing & 387 & 10.64 \\
\hline Total & 3636 \\
\hline
\end{tabular}


Table 2. (Continued)

\begin{tabular}{lrr} 
& \multicolumn{2}{c}{$\begin{array}{c}\text { Twin } \\
\text { individuals }\end{array}$} \\
\cline { 2 - 4 } Variable & $n$ & $\%$ \\
\hline $\begin{array}{l}\text { On a day you have alcoholic drink, how many standard } \\
\text { drinks do you usually have? }\end{array}$ & & \\
\hline More than 10 drinks & 19 & 0.52 \\
\hline 7-10 drinks & 89 & 2.45 \\
\hline 5-6 drinks & 182 & 5.01 \\
\hline 3-4 drinks & 744 & 20.46 \\
\hline 1-2 drinks & 2187 & 60.15 \\
\hline Don't know/Prefer not to answer & 24 & 0.66 \\
\hline Missing & 391 & 10.75 \\
\hline Total & 3636 & \\
\hline
\end{tabular}

to screen for community cases of psychological distress, based on severity, rather than diagnosing specific disorders (Kessler et al., 2002). The K6 has been found to discriminate between Diagnostic and Statistical Manual of Mental Disorders (DSM-IV) cases and noncases (American Psychiatric Association, 2000) and is sensitive in the 90th-99th percentile range of the population distribution (Kessler et al., 2002). The final phase of the scale's development included cross-validation with the Australian National Mental Health Survey (Andrews \& Slade, 2001). We used Australian K6 scoring for this study; the possible overall scores range from 6 to 30, with lower total scores (6-18) indicating no probable serious mental illness and higher total scores (19-30) indicating probable serious mental illness (Australian Bureau of Statistics, 2006a).

\section{Data Analysis}

Regression models. We used three regression-based methods to explore the association between SES and psychological distress. The first approach used mixed effects models to take into account the correlation between twins in a pair, including SES measures and potential confounders as fixed covariates, and were fitted using maximum likelihood estimation. The estimates from this model represent weighted averages of the subsequent within-pair and between-pair estimates.

To analyze the association between the differences in the outcome and the differences in the exposure variables, we used within-pair regression of the difference in the outcome and the differences in the exposures for twins in each pair (Carlin et al., 2005). Given that the distances between category midpoints were approximately the same for all noncontinuous exposures, these were treated as pseudo-continuous variables.

We also fitted within-between regression models, again using mixed effects models. These models included derived covariates representing the pair mean and the differences between each twin's value and the pair mean for the exposure variables (Carlin et al., 2005) and model parameters were estimated using maximum likelihood.

In these analyses, we did not allow different covariances for monozygotic (MZ) and dizygotic (DZ) twins in the models because the focus was on measured covariates and there was little power to

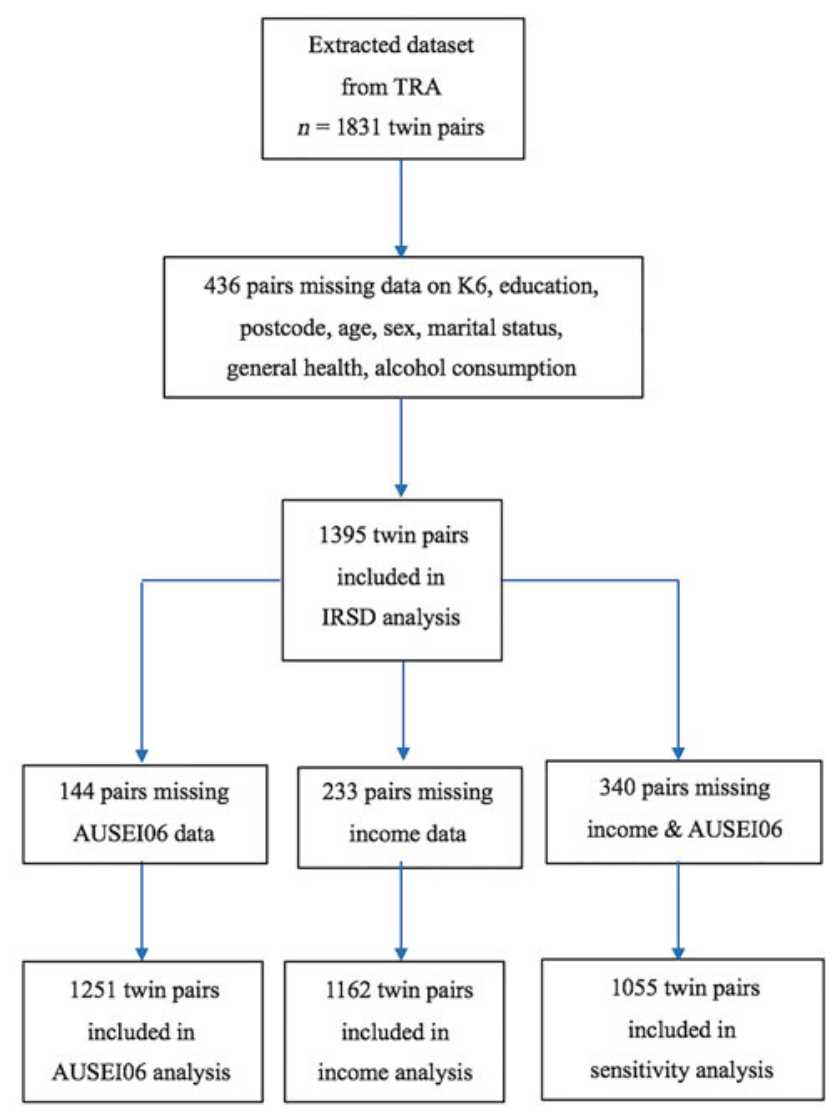

Fig. 1. Sample sizes used to analyze the associations between the K6 and IRSD.

detect differences in covariances given the different numbers of $\mathrm{MZ}$ and DZ twin-pairs.

Measured confounders. We adjusted for age, sex, general health and marital status in our analyses of the association between IRSD decile and K6 score and in our analyses of the association between the AUSEI06 and K6 scores. For the association between income category and K6 score, we also adjusted for the AUSEI06 score as occupation level is likely to influence income earned as well as psychological distress.

Maximizing sample power. To maximize the study's power, we used the greatest number of pairs possible in analyses between the $\mathrm{K} 6$ and each of the three socioeconomic indicators (see Figure 1). To analyze the association between the K6 and the IRSD, we used 1395 pairs. Both twins in each pair had complete data on the K6, education, postcode, age, sex, marital status, general health and alcohol consumption. Answers of 'Don't know / Prefer not to answer' were coded as missing values. Due to missing data for occupation and income, we analyzed the associations of occupation and income with the K6 separately in two different subsets. There were 1251 pairs who had complete data for occupation (AUSEI06 scores) and 1162 pairs who had complete data for income.

\section{Ethical Standards}

This study received formal approval from TRA and ethics approval from The University of Melbourne's Melbourne School of 


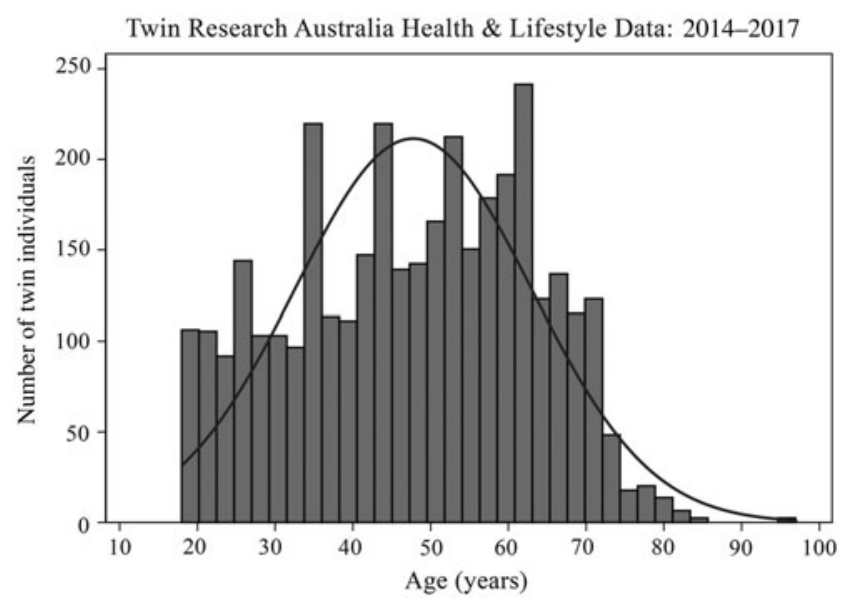

Fig. 2. Age distribution among the sample.

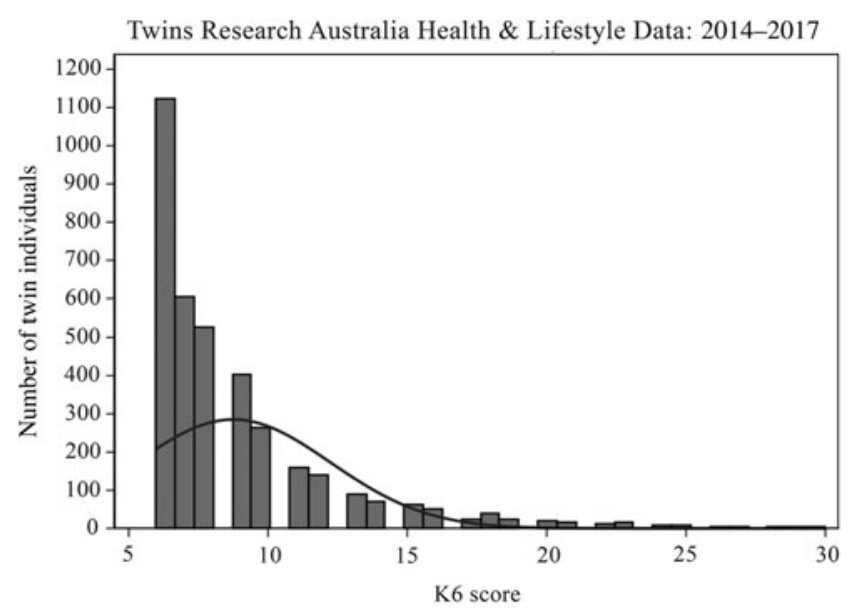

Fig. 3. Sample distribution of Kessler Psychological Distress Scores.

Population and Global Health's Human Ethics Advisory Group (Ethics ID: 1851183.1).

\section{Results}

Table 2 and Figures 2-5 describe the characteristics of the 3636 twins included in this study's sample. The majority were female (77.26\%) and MZ twins (74.64\%). Almost half the sample was 49 years or older $(49.18 \%)$. Just under half earned $\$ 52,001$ or more (46.65\%); however, the median AUSEI06 score was 67 and the median IRSD decile was 7. The median K6 score was 8, indicating no probable serious mental illness. Despite a lack of normality in the distribution of most variables among single twins, the differences in variables between twins within each pair were normally distributed.

\section{Standard Multiple Regression}

Standard multiple regression that accounted for correlations in twin-pairs showed the IRSD was not associated with the K6 $(p=.1)$, but the AUSEI06 score $(p<.001)$ and income $(p<.001)$ were strongly negatively associated with the K6 score (see Table 3).

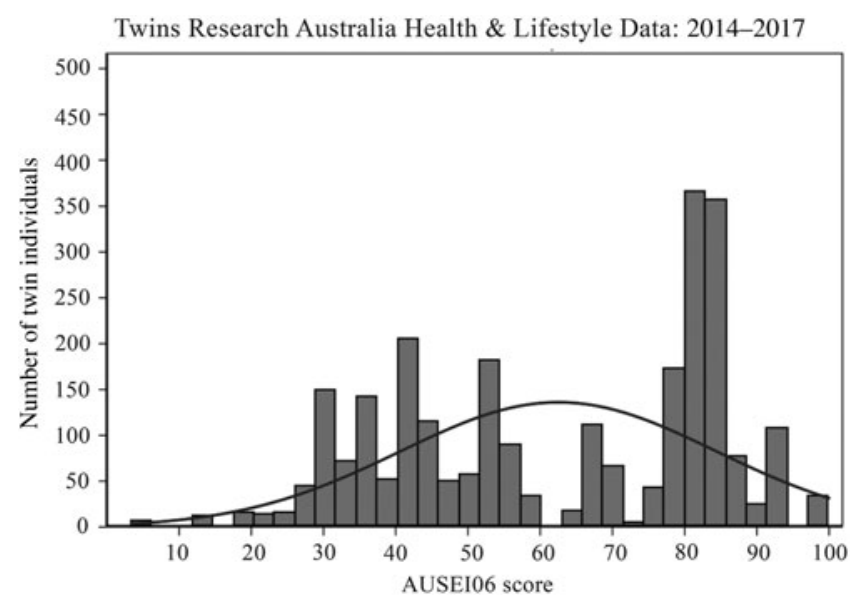

Fig. 4. Sample distribution of AUSEI06 scores.
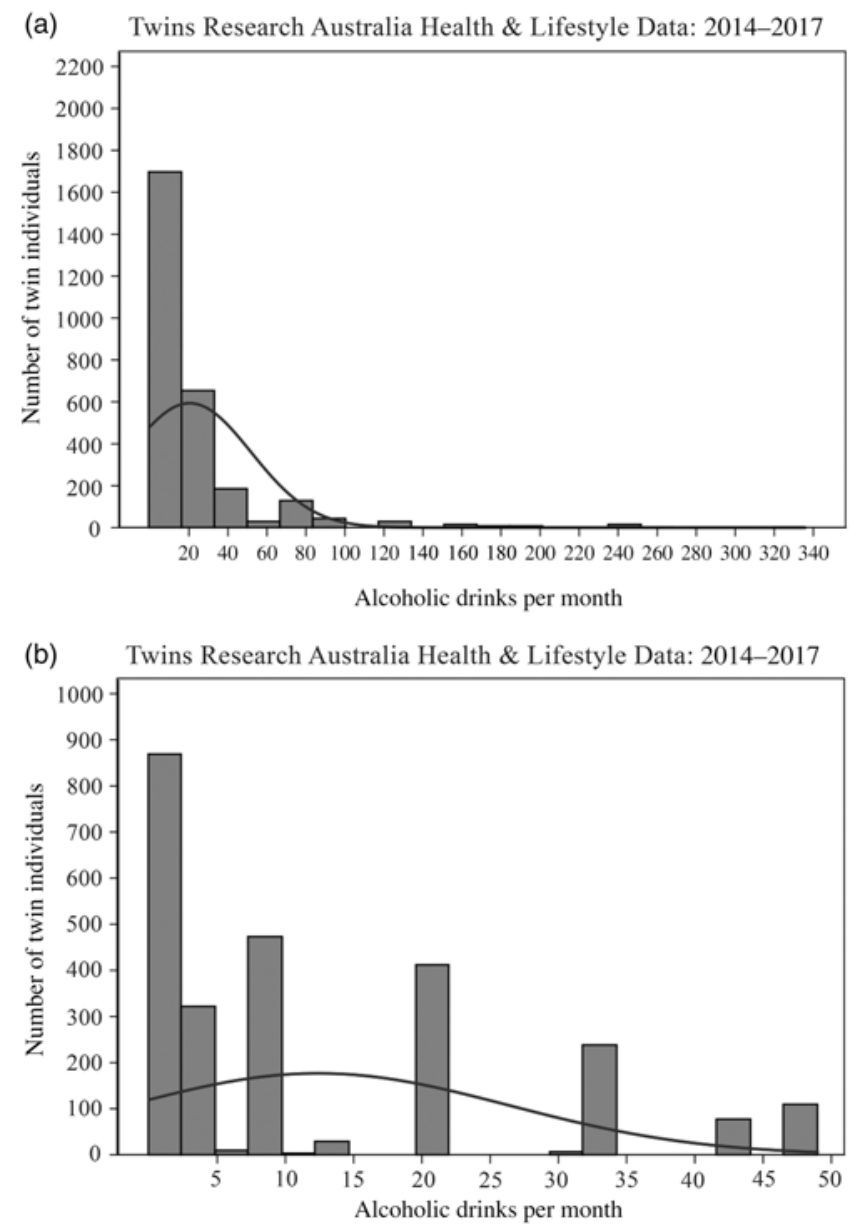

Fig. 5 Sample distribution of derived alcohol measure used in models (number of alcoholic drinks consumed per month). (a) All data and (b) Excluding outliers.

\section{Within-Pair Differences Analyses}

Within-pair analyses showed strong evidence for the association between a higher AUSEI06 score and lower K6 score as well as higher income category and lower K6 score, after controlling for genes and environment (see Figures 6 and 7). There was no 
Table 3. Generalized least squares estimates obtained from a maximum likelihood model (GLS ML) random effects, within-pair and within-between pair analyses

\begin{tabular}{|c|c|c|c|c|c|c|c|c|c|c|}
\hline \multirow[b]{2}{*}{ SES indicator } & & \multicolumn{3}{|c|}{ IRSD* $^{*}$} & \multicolumn{3}{|c|}{ AUSEI06** } & \multicolumn{3}{|c|}{ Income $e^{\star \star \star}$} \\
\hline & & Est. & $95 \% \mathrm{Cl}$ & $p$ value & Est. & $95 \% \mathrm{Cl}$ & $p$ value & Est. & $95 \% \mathrm{Cl}$ & $p$ value \\
\hline GLS ML random effects & $\beta_{C}$ & -0.034 & {$[-0.081,0.012]$} & .144 & -0.015 & {$[-0.021,-0.009]$} & $<.001$ & -0.210 & {$[-0.289,-0.130]$} & $<.001$ \\
\hline Within-pair & $\beta_{\mathrm{W}}$ & -0.021 & {$[-0.093,0.052]$} & .575 & -0.015 & {$[-0.024,-0.006]$} & .001 & -0.170 & {$[-0.283,-0.056]$} & .004 \\
\hline \multirow[t]{2}{*}{ Within-between } & $\beta_{\mathrm{w}}$ & -0.021 & {$[-0.093,0.052]$} & .574 & -0.012 & {$[-0.021,-0.004]$} & .006 & -0.182 & {$[-0.295,-0.069]$} & .002 \\
\hline & $\beta_{\mathrm{B}}$ & -0.040 & {$[-0.099,0.020]$} & .191 & -0.018 & {$[-0.025,-0.010]$} & $<.001$ & -0.215 & {$[-0.327,-0.104]$} & $<.001$ \\
\hline Likelihood ratio test & $\beta_{\mathrm{W}=} \beta_{\mathrm{B}}$ & & & .700 & & & .400 & & & .682 \\
\hline
\end{tabular}

Notes: $\beta_{C}$ is the average change in $\mathrm{K} 6$ score for a 1-unit increase in SES indicator.

$\beta_{W}$ (within-pair model) is the expected change in the difference in K6 score between twin one and twin two, for a one unit change in the difference in SES indicator between twin one and twin two. $\beta_{\mathrm{W}}$ (within-between model) is the expected change in $\mathrm{K} 6$ score for a 1-unit change in the difference between an individual's SES indicator and the twin-pair average for the SES indicator. $\beta_{\mathrm{B}}$ (within-between model) is the expected change in K6 score for a 1-unit change in the twin-pair average for the SES indicator.

*IRSD, $n=1395$ pairs. Models adjusted for age, sex, general health, marital status and alcohol.

${ }^{\star \star}$ AUSEI06, $n=1251$ pairs. Models adjusted for age, sex, general health, marital status and alcohol.

***Income, $n=1162$ pairs. Models adjusted for age, sex, general health, marital status, AUSEI06 score and alcohol.

Within-pair differences model does not adjust for age or zygosity.

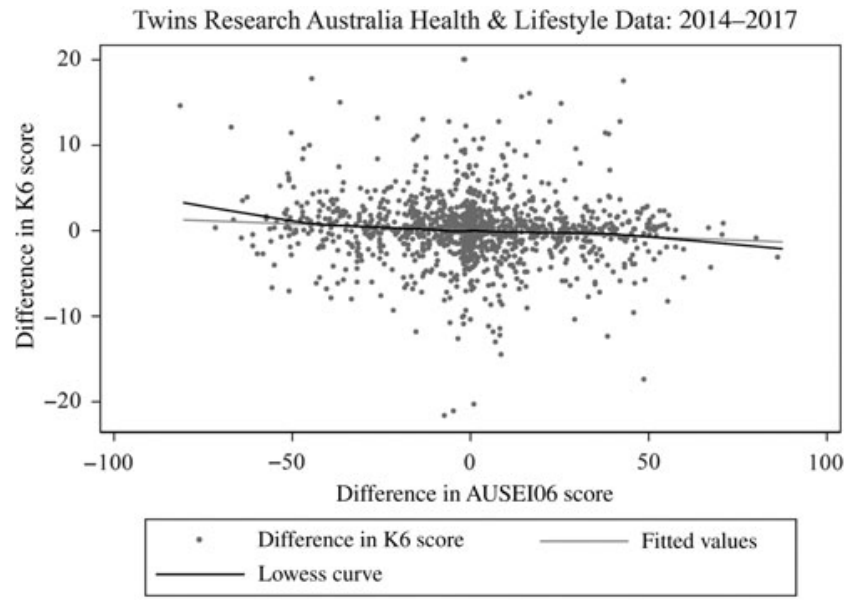

Fig. 6. Scatter plot with Lowess curve of the K6 score and AUSEI06 differences within pairs.

evidence of an association between IRSD decile and K6 score differences within twin-pairs $(p=.6)$ (see Table 3 and Figure 8).

\section{AUSEI06 Score}

For every unit increase in the difference in the AUSEI06 score (between twin 1 [first-born twin in a pair] and twin 2 [second-born twin in a pair]), the expected difference in the K6 score (between twin 1 and twin 2) decreases by 0.015 units (95\% CI $[-0.024$, -0.006 ], $p=.001$ ) (see Table 3). For a 10-unit increase in the difference in the AUSEI06 score (between twin 1 and twin 2), the expected difference in the K6 score (between twin 1 and twin 2) decreases by 0.15 units ( $95 \%$ CI $[-0.24,-0.06], p=.001$ ). This meant that a twin who has a higher AUSEI06 score than their co-twin tended to have a lower K6 score than their co-twin.

\section{Income Category}

For every unit increase (approximately $\$ 20,000$ ) in the difference in income category (between twin 1 and twin 2), the expected difference in the K6 score (between twin 1 and twin 2) decreases by 0.170 units $(95 \%$ CI $[-0.283,-0.056], p=.004)$ (see Table 3 ). For a 5-unit increase (approximately $\$ 100,000$ ) in the difference in income category (between twin 1 and twin 2), the expected

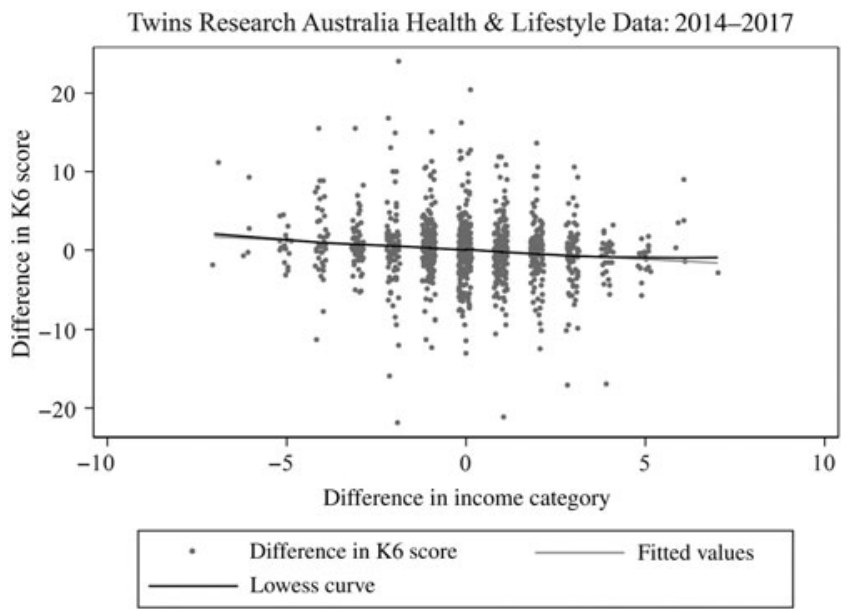

Fig. 7. Scatter plot with Lowess curve of the $\mathrm{K} 6$ score and income category differences within pairs.

difference in the K6 score (between twin 1 and twin 2) decreases by 0.85 units $(95 \% \mathrm{CI}[-1.415,-.168], p=.004)$. This meant that the individual twin within a pair who has a higher income category than their co-twin would have a lower K6 score on average than their co-twin.

\section{Within- and Between-Pair Multivariable Analyses}

IRSD decile. There was no evidence of an association between IRSD decile and K6 score when using differences between twin 1 and twin 2's IRSD deciles ( $\beta_{\mathrm{W}}$ [within-pair regression coefficient], $p=.6$ ) and the between-pair average for IRSD decile $\left(\beta_{\mathrm{B}}\right.$ [between-pair regression coefficient], $\left.p=.2\right)$ in analysis (see Table 3). As per the ABS's recommendations, we used IRSD deciles in the analysis for ease of interpretation (Pink, 2013).

AUSEI06. The between-pair estimate ( $-0.018 \mathrm{~K} 6$ score units) was similar to the within-pair estimate $(-0.012 \mathrm{~K} 6$ score units) for the association between the AUSEI06 and K6 scores. This meant that the observed association between the AUSEI06 and K6 scores was unlikely to be due to confounding and consistent with causation. The between-pair CI $(95 \%$ CI $[-0.025,-0.010])$ and withinpair CI $(95 \%$ CI $[-0.021,-0.004])$ overlapped, indicating a true 
Twins Research Australia Health \& Lifestyle Data: 2014-2017

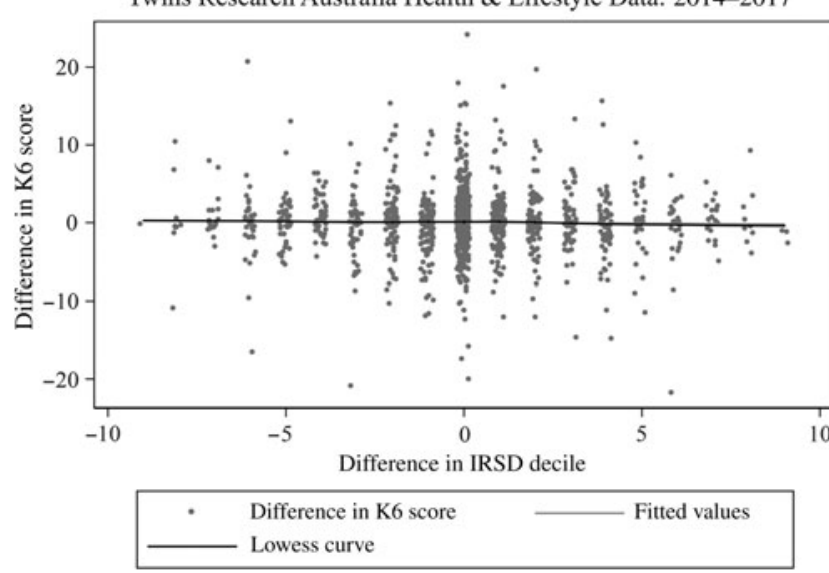

Fig. 8. Scatter plot with Lowess curve of the $K 6$ score and IRSD decile differences within pairs.

difference between these estimates was unlikely to exist. A likelihood ratio test confirmed this observation, providing no evidence against the null hypothesis that the estimates were different $(p=.4)$ (see Table 3). The true association was the within-pair estimate $\left(\beta_{\mathrm{W}}=-0.012\right.$ units), that is, the estimate representing the association, free from confounding by shared genetic and environmental factors.

Income. Again, the similar estimates $\left(\mathrm{B}_{\mathrm{B}}=-0.215\right.$ units, $95 \% \mathrm{CI}$ $[-0.327,-0.104]$ and $\beta_{\mathrm{W}}=-0.182$ units, 95\% CI $[-0.295$, $-0.069])$ meant that the observed association between income category and the K6 score was consistent with causation. A likelihood ratio test confirmed this observation $(p=.7)$ (see Table 3 ). The true association was the within-pair estimate $\left(\beta_{\mathrm{W}}=-0.182\right.$ units).

\section{Sensitivity Analysis and Robustness Checks}

Sensitivity analysis. We performed a sensitivity analysis for each socioeconomic indicator using the subset in which all twin-pairs had complete data for income and AUSEI06 scores. Similar results were found, indicating that the subset of twins with missing data was not different to the larger group (data not shown).

Robustness checks. We performed robustness checks by obtaining the residuals from the maximum likelihood random effects models for the AUSEI06 score and income category (which were approximately normally distributed), removing the $2.5 \%$ most extreme values and then refitting the models. None of the models provided substantially different results, showing the associations found in the main analysis were not driven by extreme values in the data. For example, the within-pair coefficient for the association between the AUSEI06 and the K6 changed from -0.015 to -0.013 after excluding extreme values (full data not shown).

\section{Discussion}

These results provide further support for the association between lower SES (defined as AUSEI06 score or income category) and higher psychological distress, after controlling for familial confounding. However, there was no significant association between IRSD decile and psychological distress.
The within-between model revealed that the relationships between the AUSEI06 score, income category and psychological distress were consistent with causation $\left(\beta_{\mathrm{W}}=\beta_{\mathrm{B}}\right.$; Carlin et al., $2005)$. If the relationships between any of the SES indicators and psychological distress were partially due to confounding, the between-pair estimates would be expected to be larger than the within-pair estimates $\left(\beta_{\mathrm{B}}>\beta_{\mathrm{W}}\right)$. The within-pair estimate describes the association after controlling for confounding, while the between-pair association does not. If the within-pair association was larger than the between-pair association $\left(\beta_{\mathrm{W}}>\beta_{\mathrm{B}}\right)$, this too would be consistent with causation (Carlin et al., 2005).

Our findings contrast with those of Osler et al. (2007), whose analysis of cross-sectional twin data found no evidence for an association between higher occupational class and better mental health. This may be explained by differing definitions of occupational class and mental health. Osler et al. used a combination of occupational variables to create an occupational class index, while we used occupation alone. In addition, Osler et al. used a specific depression score to measure mental health, while we used the K6, a general measure of psychological distress. The difference in findings may also be explained by variance in inequality between Danish and Australian cultures. In addition, Osler et al. used a middle-aged sample, while our study sample ranged from 18 to 97 years in age. The prevalence of common mental disorders tends to decline with age (Kessler et al., 2010); therefore, an association between occupational class and depression may be less observable in a middle-aged sample.

The results of our analyses of the association between IRSD and psychological distress are more similar to those of Cohen-Cline et al. (2018), who also used a geographical census-based index (which measures the SES of an area in which an individual lives). While Cohen-Cline et al. found a significant within-pair association between neighborhood socioeconomic deprivation and depression, our study was unable to support an association in either direction. We initially attributed this difference in results to the IRSD index being based on postcodes, which encompass large geographical areas. Therefore, twins within a pair may have been more likely to reside within the same geographical area and fall into the same IRSD deciles, resulting in a large number of twin-pairs with no difference in IRSD decile. Upon review, we found no difference in IRSD decile for 35\% of twin-pairs in our sample; conversely, $65 \%$ of twin-pairs did differ in IRSD decile (and of this 65\%, 20\% differed by 1 IRSD decile). Therefore, $55 \%$ of twin-pairs in our sample with little or no difference in IRSD decile may have contributed to a null result. (The same sample was used for all models in the analysis of the association between the IRSD decile and K6 score and no differences in results were found, see Table 3). Furthermore, we used psychological distress to define mental health, while Cohen-Cline used a specific diagnosis of depression, which may further explain the difference in results between the two studies.

Our findings provide further support for the links between low SES and poor mental health and point to the need to address the social determinants of poor mental health (e.g., affordable housing; Bentley et al., 2016) and improved working conditions (LaMontagne et al., 2014) rather than focusing on interventions targeted to individuals alone (e.g., counseling, psychology or psychotherapy), which have not appeared to have an impact on the population prevalence of mental health disorders (Jorm et al., 2017). A more effective strategy may be to focus on social determinants of health, in addition to targeted interventions for individuals. 


\section{Strengths and Limitations}

Strengths. The key strength of this study was the use of a substantial twin sample to examine the association between SES and psychological distress while controlling for shared genetic and environmental traits. Standard analyses with mixed regression models can overestimate the association (even though these account for clustering in twin-pairs). The estimates from these standard analyses are weighted averages of the true within- and between-pair estimates. Using twin data and more sophisticated modeling techniques allowed us to establish the associations after controlling for unmeasured genetic and environmental confounders.

Limitations. The limitations of twin studies have been addressed in two ways. First, the distribution of total mental health screening scores among our twin dataset (Twins Research Australia, 2018) follows a 'J'-shaped exponential curve (aside from the lower scores) similar to the distributions of mental health scores in general adult population datasets (Melzer et al., 2002; Tomitaka et al., 2018). In addition, the distribution of total $\mathrm{K} 6$ scores in our twin dataset follows the distribution of the expanded version of the K6 (K10) in a nationally representative mental health survey of the Australian adult population (Slade et al., 2011; the majority of scores indicating low levels of psychological distress, while the minority of scores indicate high levels of psychological distress).

In addition, the data are cross sectional, and therefore we cannot infer direction of causation, that is, whether lower SES results in higher K6 score (probable serious mental illness) or vice versa. In addition, occupational ANZSCO coding does not account for job stability (casual or permanent roles), which may also contribute to psychological distress. Also, ANZSCO coding does not recognize voluntary or unpaid work (Australian Bureau of Statistics, 2006b). Therefore, participants such as volunteers or stay-at-home parents would have been excluded from the AUSEI06 and K6 score analyses. Including data from these participants based on their previous occupations would have increased the sample size and refined our results even further.

Although this study used economic indicators of SES, it could be argued that SES also includes political, social and cultural resources (Galobardes et al., 2007). Including these indicators in analyses might provide more comprehensive insight into the association between SES and psychological distress.

Finally, given access to the appropriate variables, it would have been useful to control for several other confounders. Women are vulnerable to depression following the birth of a child and experience depression more often at 4 years after birth than in the first 12 months following birth (Woolhouse et al., 2015). Therefore, adjusting for children (and children's age) might have accounted for more variation in the results. This is one example of many potential factors that could be controlled for. In addition, the association may vary among different disease conditions, given those with highly disabling physical diseases also experience mental health problems (Cancer Australia, 2018; Stroke Foundation, 2018; Woodruffe et al., 2015).

\section{Conclusion}

This study provided further support for the association between poor mental health and lower occupational class and earning a lower income, after accounting for unmeasured genetic and environmental confounders.
Acknowledgments. This research was facilitated through access to Twins Research Australia, a national resource supported by a Centre of Research Excellence Grant (ID: 1079102), from the National Health and Medical Research Council. We greatly appreciate Dr Humaira Maheen's invaluable guidance in using the Australian Socioeconomic Index 2006.

Conflict of interest. None.

\section{References}

American Psychiatric Association. (2000). Diagnostic and statistical manual of mental disorders (4th ed., text rev.). Washington, DC: Author.

Andrews, G., \& Slade, T. (2001). Interpreting scores on the Kessler Psychological Distress Scale (K10). Australian and New Zealand Journal of Public Health, 25, 494-497.

Australian Bureau of Statistics. (2006a). 4817.0.55.001 - Information Paper: Use of the Kessler Psychological Distress Scale in ABS Health Surveys, Australia, 2007-08. Retrieved from http://www.abs.gov.au/ausstats/abs@.nsf /Lookup/4817.0.55.001Chapter92007-08

Australian Bureau of Statistics. (2006b). Australian and New Zealand Standard Classification of Occupations First Edition ABS cat. no. 1220.0. Retrieved from http://www.abs.gov.au/AUSSTATS/abs@.nsf/second+level +view?ReadForm\&prodno=1220.0\&viewtitle=ANZSCO\%20-\%20Australi an\%20and\%20New\%20Zealand\%20Standard\%20Classification $\% 20$ of $\% 20$ Occupations 2013,\%20Version\%201.2 Latest 26/06/2013\&\&tabname= Past $\% 20$ Future\%20Issues \&prodno=1220.0\&issue=2013,\%20Version $\% 20$ $1.2 \&$ num $=\& v i e w=\&$

Bentley, R. J., Pevalin, D., Baker, E., Mason, K., Reeves, A., \& Beer, A. (2016). Housing affordability, tenure and mental health in Australia and the United Kingdom: A comparative panel analysis. Housing Studies, 31, 208-222.

Cancer Australia. (2018). Clinical guidance for responding to suffering in adults with cancer. Retrieved from https://guidelines.canceraustralia.gov. au/guidelines/guideline_22.pdf

Carlin, J. B., Gurrin, L. C., Sterne, J. A., Morley, R., \& Dwyer, T. (2005). Regression models for twin studies: A critical review. International Journal of Epidemiology, 34, 1089-1099.

Cohen-Cline, H., Beresford, S. A. A., Barrington, W. E., Matsueda, R. L., Wakefield, J., \& Duncan, G. E. (2018). Associations between neighbourhood characteristics and depression: A twin study. Journal of Epidemiology \& Community Health, 72, 202-207.

Fryers, T., Melzer, D., \& Jenkins, R. (2003). Social inequalities and the common mental disorders: A systematic review of the evidence. Social Psychiatry and Psychiatric Epidemiology, 38, 229-237.

Galobardes, B., Lynch, J., \& Smith, G. D. (2007). Measuring socioeconomic position in health research. British Medical Bulletin, 81-82, 21-37.

Hopper, J. L., \& Seeman, E. (1994). The bone density of female twins discordant for tobacco use. The New England Journal of Medicine, 330, 387-392.

Jorm, A. F., Patten, S. B., Brugha, T. S., \& Mojtabai, R. (2017). Has increased provision of treatment reduced the prevalence of common mental disorders? Review of the evidence from four countries. World Psychiatry: Official Journal of the World Psychiatric Association (WPA), 16, 90-99.

Kessler, R. C., Andrews, G., Colpe, L. J., Hiripi, E., Mroczek, D. K., Normand, S. L., . . Zaslavsky, A. M. (2002). Short screening scales to monitor population prevalences and trends in non-specific psychological distress. Psychological Medicine, 32, 959-976.

Kessler, R. C., Birnbaum, H., Bromet, E., Hwang, I., Sampson, N., \& Shahly, V. (2010). Age differences in major depression: Results from the National Comorbidity Surveys Replication (NCS-R). Psychological Medicine, 40, 225-237.

LaMontagne, A. D., Martin, A., Page, K. M., Reavley, N. J., Noblet, A. J., Milner, A. J., ... Smith, P. M. (2014). Workplace mental health: Developing an integrated intervention approach. BMC Psychiatry, 14, 131-131.

Lorant, V., Deliege, D., Eaton, W., Robert, A., Philippot, P., \& Ansseau, M. (2003). Socioeconomic inequalities in depression: A meta-analysis. American Journal of Epidemiology, 157, 98-112. 
Marmot, M. G., Stansfeld, S., Patel, C., North, F., Head, J., White, I., ... Smith, G. D. (1991). Health inequalities among British civil servants: The Whitehall II study. The Lancet, 337, 1387-1393.

McMillan, J., Beavis, A., \& Jones, F. L. (2009). The AUSEI06: A new socioeconomic index for Australia. Journal of Sociology, 45, 123-149.

McMillan, J., Jones, F. L., \& Beavis, A. (2009). A new scale for measuring socioeconomic status in educational research: Development and validation of the Australian Socioeconomic Index 2006 (AUSEI06). Paper presented at the Australian Association for Research in Education International Education Research Conference, Canberra: National Convention Centre.

Melzer, D., Tom, B. D., Brugha, T. S., Fryers, T., \& Meltzer, H. (2002). Common mental disorder symptom counts in populations: Are there distinct case groups above epidemiological cut-offs? Psychological Medicine, 32, 1195-1201.

Osler, M., McGue, M., \& Christensen, K. (2007). Socioeconomic position and twins' health: A life-course analysis of 1,266 pairs of middle-aged Danish twins. International Journal of Epidemiology, 36, 77-83.

Pink, B. (2013). Socio-economic indexes for areas (SEIFA) 2011. Retrieved from http://www.ausstats.abs.gov.au/Ausstats/subscriber.nsf/0/22CEDA803 8AF7A0DCA257B3B00116E34/\$File/2033.0.55.001\%20seifa\%202011\%20te chnical\%20paper.pdf

Scurrah, K. J., Kavanagh, A. M., Bentley, R., Thornton, L. E., \& Harrap, S. B. (2016). Socioeconomic position in young adulthood is associated with BMI in Australian families. Journal of Public Health, 38, e39-e46.

Slade, T., Grove, R., \& Burgess, P. (2011). Kessler Psychological Distress Scale: Normative data from the 2007 Australian National Survey of Mental Health and Wellbeing. Australian \& New Zealand Journal of Psychiatry, 45, 308-316.

Slade, T., Johnston, A., Oakley Browne, M. A., Andrews, G., \& Whiteford, H. (2009). 2007 National Survey of Mental Health and Wellbeing: Methods and key findings. The Australian \& New Zealand Journal of Psychiatry, 43, 594-605.

Stroke Foundation. (2018). Clinical guidelines for stroke management 2017. Melbourne, Australia: Stroke Foundation.
Sugiyama, T., Villanueva, K., Knuiman, M., Francis, J., Foster, S., Wood, L., \& Giles-Corti, B. (2016). Can neighborhood green space mitigate health inequalities? A study of socio-economic status and mental health. Health \& Place, 38, 16-21.

Sun, C., Ponsonby, A. L., Wong, T. Y., Brown, S. A., Kearns, L. S., Cochrane, J., .. Mackey, D. A. (2009). Effect of birth parameters on retinal vascular caliber: The Twins Eye Study in Tasmania. Hypertension, 53, 487-493.

Tomitaka, S., Kawasaki, Y., Ide, K., Akutagawa, M., Ono, Y., \& Furukawa, T. A. (2018). Distribution of item responses and total item scores for the Center for Epidemiologic Studies Depression Scale (CES-D): Data from the Irish Longitudinal Study on Ageing (TILDA). PLoS One, 13, e0202607.

Twins Research Australia. (2018, July 1). Adult health and lifestyle questionnaire. Retrieved from https://www.twins.org.au/research/current-studies/ 139-health-and-lifestyle-questionnaire

Whiteford, H. A., Degenhardt, L., Rehm, J., Baxter, A. J., Ferrari, A. J., Erskine, H. E., ... Vos, T. (2013). Global burden of disease attributable to mental and substance use disorders: Findings from the Global Burden of Disease Study 2010. The Lancet, 382, 1575-1586.

Whitfield, J. B., Zhu, G., Heath, A. C., \& Martin, N. G. (2005). Choice of residential location: Chance, family influences, or genes? Twin Research and Human Genetics, 8, 22-26.

Woodruffe, S., Neubeck, L., Clark, R. A., Gray, K., Ferry, C., Finan, J., . . . Briffa, T. G. (2015). Australian Cardiovascular Health and Rehabilitation Association (ACRA) core components of cardiovascular disease secondary prevention and cardiac rehabilitation 2014. Heart, Lung and Circulation, $24,430-441$.

Woolhouse, H., Gartland, D., Mensah, F., \& Brown, S. (2015). Maternal depression from early pregnancy to 4 years postpartum in a prospective pregnancy cohort study: Implications for primary health care. BJOG: An International Journal of Obstetrics and Gynaecology, 122, 312-321.

World Health Organization. (2014). Social determinants of mental health (A thematic report). Retrieved from http://apps.who.int/iris/bitstream/ handle/10665/112828/9789241506809_eng.pdf;jsessionid=407BFFF6C7C 3D5DEB4505BAB4D797C8E? sequence $=1$ 